\title{
Media and Public Trust in Chinese Basic-Level Governments: Communication and Reliance
}

\author{
Shaogang Liao*, Jing Ouyang, Ying Pan \\ School of Public Finance and Public Administration, Jiangxi University of Finance and Economics, Nanchang, China
}

Email address:

liaoshaogang@163.com (Shaogang Liao)

To cite this article:

Shaogang Liao, Jing Ouyang, Ying Pan. Media and Public Trust in Chinese Basic-Level Governments: Communication and Reliance. Science Journal of Business and Management. Vol. 3, No. 5, 2015, pp. 145-149. doi: 10.11648/j.sjbm.20150305.12

\begin{abstract}
According to the phenomena of interaction between the citizens and governments, we can see that the public trust of Chinese basic-level governments has not improved with the function transformation, but constantly decreases. At the reality of the deficiency of public trust, the Chinese basic-level governments lost the communication ability of regaining the understanding and trust of the public and the related governance capacity. This is one of the main difficulties which the Chinese basic-level governments are facing. Under this condition, those higher government institutions who have high public trust and strong communication ability and media should undertake the responsibility of remodeling the Chinese basic-level governments' public trust.
\end{abstract}

Keywords: Chinese Basic-Level Governments, Public Trust, Communication Ability

\section{The Governments' Public Trust and Governments' Public Relations}

It is stated that the governments' public trust is an ability that the governments gain the public trust and support through self behavior. It comes from the subjective judgments or value judgments of the social public towards the governments' behavior. It is a psychological response of the public to the governments' reputation and image. It not only includes the public's understanding, emotion, attitude, hope and belief regarding the whole governments' image, but also reflects that the public is willing to cooperate with governments in order to improve the efficiency of public administration.

The public trust of governments is closely related to the governments' public relations because the governments' public relations are its public communication activities, shaping the good image and public trust of governments. The governments' public relations are not only activities communicating with the public, but also unique image-management ability. It takes the government as the main body, two-way communicating with the public, using various spread methods in order to obtain the support, trust and cooperation of the public so as to build the good image of government and obtain public trust. The essence of the government public relations is to coordinate the relations between the government and the public through a series of communication and exchange in order to obtain the understanding and trust of public. How to communicate effectively with the public is the key point of public relations of any government. In the new age of information getting more open and transparent, many administrative organizations and their leaders in the world actively carry out the public relation activities, public media as the communication intermediary. They pay more attention to the communication and exchange with the media, making the public understand more about their work through the media, persuading the public to support their administrative measures in order to win the wide support and trust of the public opinion and the society.

According to the three-element principle: subject, medium and object of the public relations, the governments are the subjects of public relations and the public are the objects of public relations, within the public relations of governments. The information spreading complying with professional ethics is the medium connecting the subjects with objects. As the link of information spread in the modern society is the public media, the government public relations is the communication and exchange between the government, public and media. Through the modern media means, such as television, broadcast, network, newspapers and so on, the governments set up the message passing relations with the public in order to narrow the gap between the ideal image and real image of the governments and build the governments' public trust. The goal 
of the government public relations is setting up the official and people interaction system, in order to enhance the understanding, grow trust, reach consensus, and reach cooperation. As show below:

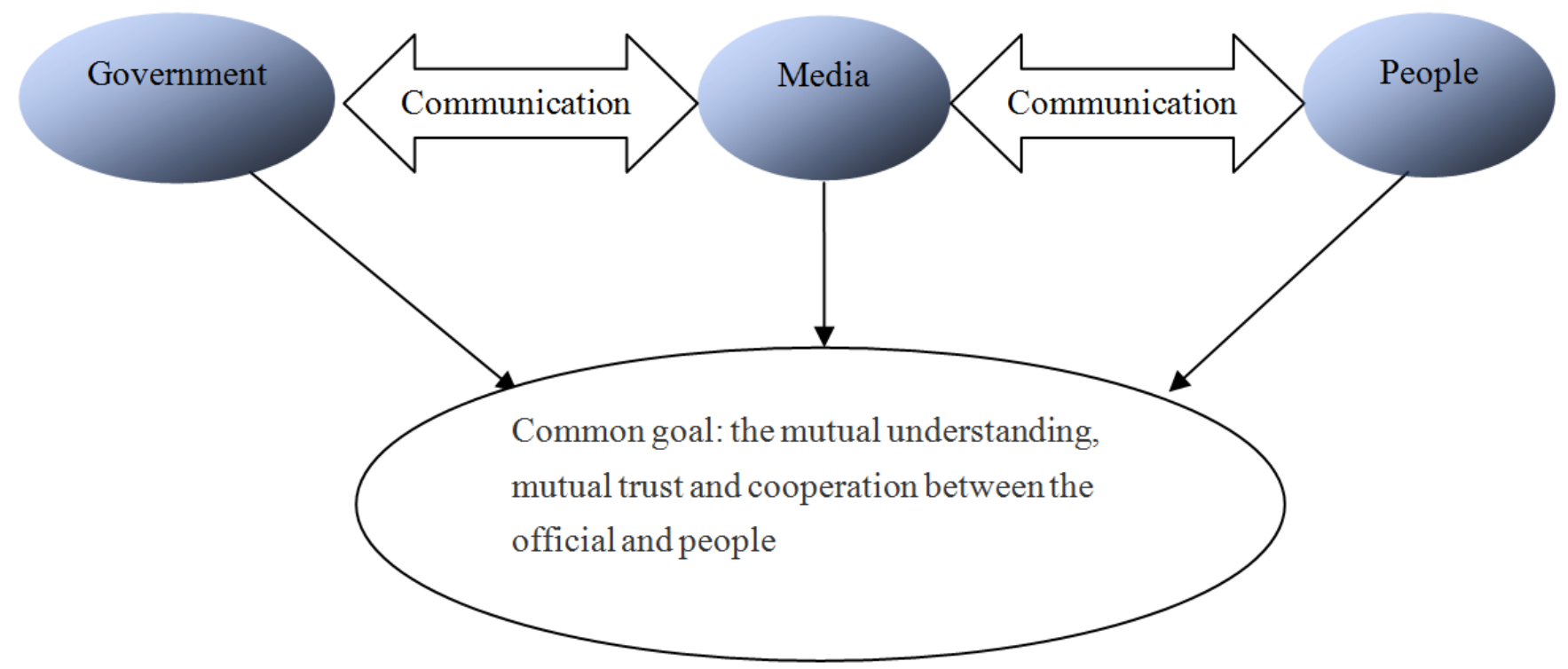

Chart 1. Chart of the operation of government public relations.

The chart above vividly illustrates that operation of the government public relations are not only the single behavior of government, but also the two-way interaction between the government and the public, among which the modern public media becomes the main communication platform and medium between the governments and the public. Since the information spread is the main content and key element of the operation of the government public relations, it determines whatever the governments, the public or the media must obey for the publicity principle based on facts. This is the basic operating model of the government public relations. When a public crisis happens, the grapevine is spread at the beginning, which leads to a distortion of information spreading; even rumors are afloat, creating confusion among the public. According to the publicity principle of public relations, it requires the government to announce the truth as soon as possible, be proactive with releasing the latest information before the the grapevine spread, reducing speculation in society, explaining to the public about measures, putting off public doubts and eradicate the rumors in society quickly.

In theory, governments at all levels could set up their own fine images equally and freely through the public relations in order to get the understanding, trust and support of the public. In practice, in public relations activities, as governments at all levels have different abilities of spreading the technology and information, their abilities of information communication and relevant public relations reflect a distinctive difference. For example, compared with the central government and provincial governments, the county and village governments have difficulties to conduct the public relations activities with the help of the media, which is more public and authoritative. On the other hand, Chinese Medias are structured like the Chinese governments, from the central level, provincial level, city level to county level, which sets the differences of public relation abilities of the governments at all levels. Obviously, the ability of using the media resources of the county and village governments which are at the lowest end of administrative system is weaker than on other government levels. Their communication ability and relevant public relations ability appear even weaker as well. In fact, the lack of the public relations ability is one of the main factors leading to a decline in the Chinese basic-level governments' public trust.

\section{The Chinese Basic-Level Governments with the Lowest Public Trust}

Although the governments at all levels are in the same political and system environment, their public trust appears with a big difference. The sampling survey, conducted by the Chinese Academy of Social Sciences on the residents in the 28 cities and provinces of China in 2007, shows that the central government was the most trustworthy, and the local governments were less trustworthy. The Chinese trust survey issued by Moderate Prosperity Journal in the past years showed that most interviewees quite trust the central government, yet more than $70 \%$ of interviewees did not believe in the Chinese basic level governments. Besides this, there is a ballad around, which goes like this: The central government is benefactor, the provincial government is relative, the regional government is good man, the county government is bad man, and the town government is enemy. It reflects that the public trust in the government declines along the level of the governments. The public trust to the basic level government is the lowest. Some scholars' field survey to the national rural areas further verified the public trust to the governments showed in the ballad, with the grassroots' trust to the governments of different levels decreased step by step. 
Since the 21st century, along with the cancel of the agricultural tax and fee and the development of the construction of new villages, various kinds of resources, allowance, investments were brought to the towns. The function of the Chinese basic level governments transferred from "resources absorption" to "resources to the countryside and services to the countryside". The transformation of the government function ought to make the Chinese basic level governments' public trust improve and make the interaction between the official and public become harmonious. However, the reality of interaction between the official and public in the post-tax-and-fee era showed that instead of improvement, the public trust to the basic-level governments continuously lowered. According to the continuing survey regarding the public trust to the governments conducted by the program group, named "Ten Year Observation to the Hundred Villages", belonging to the Chinese Village Research Institute of Central China Normal University from 2009 to 2010, the villagers trust proportion to the central government, country level governments and township-level governments were $70.6 \%, 10.3 \%$ and $6 \%$ respectively. Obviously, a series of benefit farming policy didn't change the distrust of the basic-level mass to the Chinese basic-level governments. Asides, People's Daily issued a commentary on November 3, 2011 that those mass disturbances, which happened all over recently, may it be the Meng Lian Event, Wengan Event several years ago, or the Zengcheng Event, Zhili Event in this year, all had the same feature, with the public having less trust in the local governments and officials. This article pointed out that "these mass disturbances had the highly similar operational logic, which alarms us to pay more attention to the trust crisis in the relations between the basic-level officials and public"."Basic-level officials actually act as the image spokesperson of local governments and the Communist Party. So their ability and style of work affects the local people's comments on the ruling party." At last, the article warned that "if the trust crisis regarding the local governments is growing, it would directly endanger the ruling foundation."

The reason for Chinese basic-level governments' public trust decline varies. However, the main reason is that the basic-level governments are the only governments communicating with the public directly, being in the first line facing the various contradictions, whose functions are linked to those behaviors close to public's benefits, such as levy, collection, punishment and the like. In the era of tax and fees, Chinese basic-level governments were described by the farmers as "the three demand governments", which was to say: demanding money, demanding food, demanding lives (the family planning policy). These behaviors claiming from the public seriously affect the image of Chinese basic-level governments. With the benefit farming policy in post-era of tax and fees, the public trust of Chinese basic-level governments still is related to the actual treatment in benefits and governance pattern, which is to say the Chinese governments still haven't set up the idea and managing method of service-oriented government. On the other hand, the reality of lowest public trust of Chinese basic-level governments is related to the image building of basic-level governments and officials, conducted by the public media. As we all know, in the various kinds of literary reports, Chinese basic-level governments or officials are described as bad person doing some bad things. So the image of Chinese basic-level governments has "bad person" imprinted on the people's minds so that the public have no love for the Chinese basic-level governments and officials and distrust them as well.

The Chinese basic-level governments' difficulties are that once the public creates a fixed mindset, the Chinese basic-level governments could not remove the bad image by relying on controlling their own words and actions. That is to say that the Chinese basic-level governments which lack in public trust actually lost the ability of efficiently communicating and exchanging with the public and lost the ability of rebuilding the image and public trust by themselves through their own words and actions. According to the critical commentary published on the People Daily, once the Chinese basic-level governments get into trust difficulty, they would not gain recognition whatever measures they are taking. Accordingly, the basic-level officials' say "whatever we do and whatever we say, the public would not believe it". In this reality, we must rely on the power of a third party to help the Chinese basic-level governments to carry out the public relation activities and rebuild the image of Chinese basic-level governments.

\section{Improving the Public Trust of the Chinese Basic-Level Governments: Strengthening the Ability of Communication}

When the media and public lack the basic trust in the Chinese basic-level governments, the governments lack of public relations ability and could not communicate and exchange with the public efficiently. Some medium who has the public relation ability, for example, the superior governments and media, should undertake the responsibility of helping the Chinese basic-level governments to step off the trust crisis, helping the Chinese basic-level governments to regain the public's understanding and trust and improving their public trust.

In fact, the public relations of the superior governments and media are related to whether the Chinese basic-level governments could regain the public trust. The Qian Yunhui Event serves as an example. When this event happed, the guess and rumor which were not confirmed were spread rapidly the first time. Although Leping City Government held the press conference and made a quick response after the event, the public and media barely believed the government. However, it triggered off the fiercer guess and query. Fortunately, the superior government of Leqing city got involved in the event, taking the place of Leqing City and becoming the subject facing the public crisis. It has set up the special investigation team, held the press conference; 
announced the latest survey result and responded to the query of the media and public. It also invited the media authority News Investigation Program of CCTV for in-depth reports on the event, clarifying the facts and answering the public's questions. In the end, it made the public believe the truth and recovered the public trust.

Obviously, without the intervention of the superior government and special investigations, without the objective and in-depth report of the media authority, just relying on the explanation of the basic-level government, the event could not be clarified rapidly. The local government could not respond to the public relation crisis quickly. The Chinese basic-level government understands that at the background of missing public trust, once getting into trouble, it will be hard to defend themselves, even stimulating the wider and severer criticism. When the unexpected public incidents happen, the action of the Chinese basic-level governments is to adopt various ways in order to avoid the incidents becoming public events. However, the "avoid" attitude of the Chinese basic-level governments sometimes would force them into a more passive position. The event happening in Yihuang County, Jiangxi Province can illustrate this point. After the event happened, the local officials dealt with it according to the general way to avoid making it bigger and escalating, not only explaining to the public, but also answering to the public's questions.

Looking back to the Yihuang event, we can discover that "Silent state" of the local government exposed their inability of communication. Although Yihuang Government responded to the public through their official website in the afternoon on 12 September, obviously, in such a situation, any explanation of the government could not be understood and trusted by the public. In another words, in the reality of losing the public trust, the public does not trust the basic-level governments again. It requires the superior governments or authoritative media to undertake the responsibility of explaining the policy, detailing the process of the event and to undertake the role and responsibility of rebuilding the images of basic-level governments. It is in order to help both sides to understand and trust each other, reaching a consensus, solving the problem in the end. For example, since 2008, the Yihuang county government had communicated and negotiated with parties for more than 50 times about the standard of demolition compensation. When the event happened, the media not only didn't reveal both sides' contradiction and appealed to help those looking for reasonable ways of solving problems, but also pushed the event to a new high with the "eye catching" commercialized operation logic. For example, a photo with burning quilts falling down from the building was "described" as a person being on fire like a fireball and jumping from a building. This photo became the one with the highest reprinting rate by the media and the press.

In this public event, the media as the medium of communication not only did not comply with the fact-based principle of public relations, did not help the public to calmly understand the event, but also did not help both sides to understand and communicate with each other, by standing in a neutral position, to reach a consensus and solve the problems.
However, the media queried the government, filled with senses of self righteousness, and extremely propagated the weak image of the party. It pushed the event to a new high for not helping the basic-level government to set up the good mechanism, but digging the news effect. When the government faced criticism which was not objective and rational, it did not carry out the efficient public relation activities, asking for the help by the third party - the authoritative superior governments or media to do the work of explanations, illustration and communication. Furthermore, the superior government, which should undertake the public relation responsibility, kept silent and did not give any explanations nor illustration to the public. It just calmed down the public with removing the officials. When the event calmed down, the removed officials made a return without any explanations or illustration. The action in which the superior government ignored the communication and exchange with the public must lead to the new query. It not only did not help the Chinese basic-level government to rebuild the public trust, but also affect their own authority negatively.

If we look at the relations between the public events and Chinese basic-level governments' public trust from the angle of public relations, we could know that the public events are not horrible. It could become the chance to rebuild the images of the governments and reform the governance pattern of the basic governments. The key point is for the governments to have the consciousness and ability of public relations to communicate with, and explain to the public actively. The understanding and trust of the public to the governments are set up through the process of communication and exchange. When the crisis happens, and if the superior governments have the capacity of launching the public relation activities in time, they could not only redeem the trust of public to the basic-level governments, but also embody the initiative and quick response of the governments. Yet more importantly, only if the superior governments help the basic-level governments to leave the trust crisis, the grassroots governance could be able to enter the positive cycle and the public crisis events would not be explosive. On the contrary, if the superior governments lack of public relations consciousness, it would lead to the continuing loss of public trust of the basic-level governments. And it would also affect the public trust in the superior governments accordingly.

\section{Conclusion}

When the public lack the basic trust in the Chinese basic-level governments and look at them as the bad governments, the communication with the officials and governments will not be sincere, tolerant, rational, common-sense and cooperative. When the public lack the basic trust in the basic-level governments, once the conflict between the officials and public happen, seldomly people would comment the reason of the events calmly, rationally and objectively. More importantly, a Chinese basic-level government which lacks basic public trust definitely lacks the capacity of carrying out the public policy, ability of 
mobilization and implementation. If things continue this way, some active and effective public governance goals are difficult to be implemented effectively and the basic-level governments are difficult to build a virtuous circle model of governance. So the basic-level governments need to rebuild the public trust soon to realize the effective and ordered governance.

The analysis of the article is in order to illustrate that the medium which has the public relation ability - the superior governments and authoritative media should take the responsibility to help the Chinese basic-level governments to rebuild the cooperative relations with the public and obtain the public's trust. However, the premise is abiding by the openness principle of objective facts. During the public events which were related to the Chinese basic-level governments' image, the superior governments and media should be the main subjects to deal with the public relations and to undertake the role of bridge-connecting the basic-level governments with the public. They were neutral to reflect the appeal of the both sides objectively and helped the public to understand the real situation and to communicate with each other. Their goals were improving the understanding, reaching consensus, looking for the ways of solving contradiction and facilitating collaboration. Destroying a public organization's image is very easy. However, rebuilding the image is a hard project. During the operation of public relations concerning the basic-level governments' images, it needs the superior governments to have the serious and cautious attitude and requires the media to keep neutral. They should not place the basic-level governments in an injustice and trustless position in advance. They should understand the behavior of the basic-level governments from the institutional ecology and system environment which basic-level governments are in, revealing the root of various problems and conflicts in the basic-level society. Only this can help the Chinese basic-level governments to leave the crisis of confidence.

\section{References}

[1] Ma Caichen, 2006.The Purchase of Public Service: Bridge Connecting Government and the Society. Financed Trade Economics 3: 7.

[2] Chen Haotian, the Public Trust of Basic-level Government: the Political Logic of the Rural Economic Development in the Benefiting Farming Period, 2011

[3] Chinese News Websites. Chinese Common People Most Trusting the Central Governments Implies the Worries About the Abuse of Power of the Basic-level Governments.2007

[4] Gao Weixing,. The Analysis of the Lost and Rebuilding of the Basic-level Governments' Public Trust. Chinese Public Administration 2005.

[5] Ju Yananzhu, Public Relations, Shanghai, "Fudan University Publishing House",2010.

[6] Research Center of Moderate Prosperity, Chinese Credit Well-off Index Over the Years, Chinese Well-off Website http://www.chinaxiaokang.com/xkzs/

[7] Wang Shiquan,Xu Gai. The Relations between Governments and Media on the Background of Information Age. Chinese Public Administration 2011.

[8] Wu Yuzong. The Analysis of Strengthening the Governments' Public Relations. Social Science Rearch, 2003.

[9] Xiao Tangbiao, Wang Xin, the Transition of Political Credit of Chinese Farmers----the Tracking Study to the 60 Villages in 5 Provinces(1999-2008) Management World 2010.

[10] Dai Wei. Research on the effective path of improving the public trust of the local government in the new media era. Journal of Changsha University.2014.

[11] Song Jilang.Research on the construction of public trust in the basic level government of China. Management Observer,2015. 